\title{
Preparation of phosphorous slag-based cementitious material with high early strength and its concrete properties
}

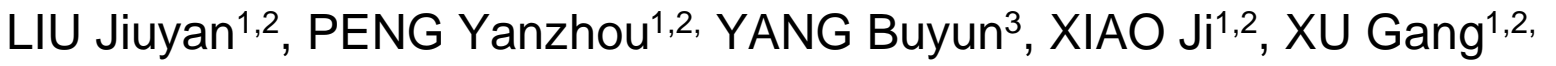 \\ ZHANG Jun ${ }^{1,2}$
}
1.China Three Gorges University Key Laboratory of Geological Hazards on Three Gorges Reservoir Area, Minstry of Education, Hubei Yichang 443002;

2. College of Civil Engineering and Architecture, Hubei Yichang 443002

3. Xi'an University of Technology, Xian Shanxi 710048

Corresponding author: College of Civil Engineering \& Architecture, China Three Gorges University, China; E-mail: pnyzh@163.com(Y. Peng).

Master candidate, College of Civil Engineering \& Architecture, China Three Gorges University, China; E-mail:869802188@qq.com (Liu)

\begin{abstract}
KEYWORDS: Rapid hardening; High early strength; Phosphorous slag; Alkali-activated cementitious material; Microstructure;

ABSTRACT: The phosphorous slag-based cementitious material (PSBCM) with rapid hardening and high early strength was obtained by incorporation of graphite tailing powder, Portland cement, silica fume and mineral material $\mathrm{A}$. The microstructure of hardened paste was investigated by Scanning Electron Microscope. Based on the optimal mix proportion of PSBCM, phosphorous slagbased concretes with different strength grades, i.e. C30, C40 and C50, were prepared and their physical and mechanical properties were tested. The results showed that the optimal mix proportion of PSBCM was that the content of phosphorous slag was $79 \%$, while the contents of graphite tailings, Portland cement, mineral material A and silica fume were 5\%, 9\%, 5\% and 2\%, respectively. As the incorporation of sodium silicate (5\%, Cal.as $\mathrm{Na} 2 \mathrm{O})$ as well as chemical A (1\%) in PSBCM, the 1-d compressive strength and flexural strength of the material were $16.1 \mathrm{MPa}$ and 3.5 MPa, respectively, and the initial setting time was $30 \mathrm{~min}$. Scanning Electronic Microscope confirmed a rapid hardening characteristic of this PSBCM and a very compact microstructure, which would endow the hardened paste with a high early mechanical property. The experiments of properties of PSBCM concretes demonstrated that these concretes has a high early strength, and the workability of PSBCM concrete was better than that of Portland cement concrete with the same strength grade.
\end{abstract}

\section{INTRODUCTION}

Phosphorus slag is a kind of industrial waste generated during the process of manufacturing yellow phosphorus by electric furnace ${ }^{[1]}$ and its chemical compositions mainly are $\mathrm{SiO}_{2}, \mathrm{CaO}$ and $\mathrm{Al}_{2} \mathrm{O}_{3}$. The total content of $\mathrm{SiO}_{2}, \mathrm{CaO}$ is more than $85 \%$ (by weight) and the $\mathrm{SiO}_{2} / \mathrm{CaO}$ ratio ranges from 0.8 to 1.4. Ground granulated electric furnace phosphorous slag (PS) possesses a glassy microstructure which is similar to that of granulated blast furnace slag after being quenched when it is still melted and the weight percentage of the glassy structure could be as high as $90 \%{ }^{[2]}$. Therefore, ground granulated electric furnace phosphorous slag may be used as a potential cementitous material ${ }^{[3-4]}$.

With the continuous development of social economy, the period of peak of infrastructure construction in our country will soon transit to that of large-scale reinforcement. Therefore, the preparation of new rapid repair materials with high early strength is of great importance on the fast repair and reinforcement of the existing infrastructure. In this paper, the early strength and work performance of phosphorous slag-based cementitious material based on the previous study were improved by the incorporation of mineral material $\mathrm{A}$, retarder $\mathrm{K}$ and silica fume. The Scanning Electronic Microscope was used to study its microstructure. Furthermore, three strength degrees of 
phosphorous slag-based concrete specimens were prepared to test its physical and mechanical properties.

\section{EXPERIMENTAL PROGRAM}

\section{Materials}

Phosphorous slag (PS): granulated electric furnace phosphorous slag produced by Yichang Yatai Chemical Co., Ltd (Hubei Province, China). Its specific surface area is $397 \mathrm{~m}^{2} / \mathrm{kg}$; Graphite tailing powder (GT): graphite tailing supplied by Zhongke Hengda graphite Co., Ltd, and ground in SM 50 Mill for 50 mins. Its surface area is $305 \mathrm{~m}^{2} / \mathrm{kg}$; Cement: ordinary Portland cement P.O 52.5, which complies with Chinese Standard GB 175-2007, from Huaxin (Yidu, Hubei Province, China) Cement Co. Ltd. The compressive and flexural strength at 3-d age were $4.5 \mathrm{MPa}$ and $25.7 \mathrm{MPa}$, respectively while that of $28-\mathrm{d}$ were $7.8 \mathrm{MPa}$ and $53.5 \mathrm{MPa}$, respectively; Mineral material A: a type of mineral material whose mainly chemical composition is $\mathrm{CaO}$, and its sieve quantity of $80 \mu \mathrm{m}$ square hole sieve is approximate 12\%; Silica fume (SF): undensified silica fume with average particle size of $0.18 \mathrm{um}$ provided by Wuhan Haoyuan Chemical Building Material Co. Ltd. The density and specific surface area of SF is $2.2 \mathrm{~g} / \mathrm{cm}^{3}$ and $20000 \mathrm{~m}^{2} / \mathrm{kg}$ respectively. Furthermore, a chemical (abbr. K) was used to modify the setting time of phosphorus slag-based material. The pertinent chemical and physical properties of PS, GT, cement, mineral A and SF used in this study are given in Table1.

Table 1. Chemical composition of raw materials (by the percentage of mass $1 \%$ ).

\begin{tabular}{cccccc}
\hline No. & $\mathrm{SiO}_{2}$ & $\mathrm{Al}_{2} \mathrm{O}_{3}$ & $\mathrm{Fe}_{2} \mathrm{O}_{3}$ & $\mathrm{CaO}$ & $\mathrm{MgO}$ \\
\hline PS & 38.09 & 3.85 & 0.33 & 43.64 & 1.98 \\
$\mathrm{GT}$ & 62.74 & 15.02 & 4.44 & 1.94 & 1.72 \\
P.O & 20.46 & 4.60 & 2.95 & 61.50 & 1.31 \\
$\mathrm{~A}$ & 4.92 & 1.5 & 0.38 & 65.1 & 15.87 \\
$\mathrm{SF}$ & 91.97 & 0.22 & 0.11 & 0.91 & 0.60 \\
\hline $\mathrm{No}$. & $\mathrm{K}_{2} \mathrm{O}$ & $\mathrm{Na}_{2} \mathrm{O}$ & $\mathrm{SO}_{3}$ & $\mathrm{P}_{2} \mathrm{O}_{5}$ & Loss \\
\hline PS & 3.05 & 0.372 & 1.27 & 3.45 & 0.52 \\
$\mathrm{GT}$ & 3.20 & 0.459 & 2.66 & 0.22 & 6.83 \\
P.O & 0.90 & 0.25 & 4.87 & 0.18 & 4.3 \\
A & 0.17 & 0.25 & 0.45 & 0.03 & 1.1 \\
SF & 1.21 & 0.27 & 0.30 & 0.22 & 2.6 \\
\hline
\end{tabular}

Experimental methods

The strength (compressive and flexural) of phosphorous slag-based cementitious material specimens were tested according to Chinese Standard GB/T17671-1999 while properties of concrete were performed according to GB/T50081-2002.

\section{RESULTS AND DISCUSSIONS}

Preparation of phosphorous slag-based cementitious material (PSBCM)

The previous study ${ }^{[7]}$ demonstrated that when phosphorus slag mixed with a certain content of ordinary Portland cement and graphite powder, its paste strength could achieve the anticipated target with 1-d flexural strength was more than or equal to $3.5 \mathrm{MPa}$, and 1-d compressive strength was more than or equal to $16.0 \mathrm{MPa}$. However, its mortar strength had not yet reached this goal, so on the basis of previous study, the early strength of PSBCM was enhanced by the incorporation of mineral material A.

Effect of mineral A on strength of PSBCM

A certain content of mineral material A (3\%, 5\%, and $7 \%)$ was mixed to explore its suitable content to improve the early mortar strength of PSBCM. The mix proportion of PSB-A specimens and the compressive and flexural strength results of these specimens are summarized in Table 2.

From Table 2, it is noted that the addition of 5\% of mineral material A gave PSBCM the highest strength, with flexural strength and compressive strength were $3.4 \mathrm{MPa}$ and $14.1 \mathrm{MPa}$, respectively. But as the content increased further, the strength decreased faster. On the one hand, the 
incorporation of mineral material A made the alkalinity of mixture system improved, which accelerated the hydration of phosphorus slag to raise the strength of PSBCM, however on the other hand, as the content of mineral material A continued to augment, the number of $\mathrm{Ca}^{2}+$ ions combined with silicate were increased, not only resulting in shorting the setting time of PSBCM ${ }^{[8]}$, but also reducing the degree of hydration of phosphorus slag thus brought the strength down.

Table 2. Effect of content of mineral A on the strength of PSBCM.

\begin{tabular}{|c|c|c|c|c|c|c|}
\hline \multirow[t]{2}{*}{ No. } & \multicolumn{5}{|c|}{$\begin{array}{l}\text { Composition of cementitious } \\
\text { materials }(\%) \text { (by weight ratio) }\end{array}$} & \multirow{2}{*}{$\begin{array}{l}\mathrm{Na} 2 \mathrm{SiO} 3 \\
\text { (Cal.as } \\
\mathrm{Na} 2 \mathrm{O} \text { ) }\end{array}$} \\
\hline & P.S & P.O & GT & \multicolumn{2}{|l|}{$\mathrm{A}$} & \\
\hline PSB-A-0 & 85 & 10 & 5 & \multicolumn{2}{|l|}{0} & $5 \%$ \\
\hline PSB-A-3 & 82 & 10 & 5 & \multicolumn{2}{|l|}{3} & $5 \%$ \\
\hline PSB-A-5 & 81.0 & 9.0 & 5 & \multicolumn{2}{|l|}{5} & $5 \%$ \\
\hline PSB-A-7 & 79.0 & 9.0 & 5 & \multicolumn{2}{|l|}{7} & $5 \%$ \\
\hline \multirow[t]{2}{*}{ No. } & \multicolumn{3}{|c|}{$\begin{array}{l}\text { flexural strength } \\
(\mathrm{MPa})\end{array}$} & \multicolumn{3}{|c|}{$\begin{array}{l}\text { compressive strength } \\
(\mathrm{MPa})\end{array}$} \\
\hline & $1 d$ & $3 d$ & $28 \mathrm{~d}$ & $1 d$ & $3 d$ & $28 d$ \\
\hline PSB-A-0 & 2.5 & 4.7 & 8.6 & 12.7 & 21.6 & 55.2 \\
\hline PSB-A-3 & 3.1 & 4.8 & 9.8 & 13.5 & 27.1 & 48.9 \\
\hline PSB-A-5 & 3.4 & 5.0 & 9.5 & 14.1 & 28.0 & 49.2 \\
\hline PSB-A-7 & 2.1 & 3.2 & 6.0 & 9.2 & 22.6 & 40.7 \\
\hline
\end{tabular}

Note: 1: the ratio of PS/P.O remains 0.8 0.9; 2: $\mathrm{Na}_{2} \mathrm{SiO}_{3}\left(\mathrm{Cal} . \mathrm{as} \mathrm{Na}_{2} \mathrm{O}\right)$ accounted for the weight of binder.

Effect of retarder $K$ on the setting time of PSBCM

The setting time of PSB-A specimens was greatly decreased for the incorporation of mineral material $\mathrm{A}$, thus an appropriate content of retarder $\mathrm{K}(0.5 \%, 1 \%$, and $1.5 \%)$ was added to adjust the setting. The mix proportion of PSB-K specimens were obtained in Table 3.The setting time results of these paste specimens were given in Figure 1.

It is demonstrated from Figure 1 that the retarder $\mathrm{K}$ had a good retarding effect on PSBCM, the more the dosage of retarder was, the longer the setting time was. The retarding mechanism of retarder $\mathrm{K}$ was that the reaction of ions ionized from retarder and ions from mixture system generated insoluble salt wrapped on the surface of phosphorus slag, which preventing the hydration process ${ }^{[8]}$ and reducing the concentration of $\mathrm{Ca}^{2+}$ ions of the solution. It led to the reduction of the speed of generation of C-S-H gel and hydrated silicon aluminum acid calcium gel, thus resulting in retarding. According to the actual requirement of setting time of cementitious materials, the dosage of retarder was $1 \%$.

Table 3. Mix proportion of PSBCM containing retarder $\mathrm{K}$.

\begin{tabular}{lllllll}
\hline \multirow{3}{*}{ No. } & \multicolumn{4}{l}{$\begin{array}{l}\text { Composition of } \\
\text { cementing materials(by } \\
\text { weight ratio })\end{array}$} & $\begin{array}{c}\text { Retarder } \\
(\mathrm{K})\end{array}$ & $\begin{array}{c}\text { Na2SiO3 } \\
(\mathrm{Cal} . \mathrm{as}\end{array}$ \\
\cline { 2 - 5 } & P.S & P.O & GT & A & & Na2O $)$ \\
\hline PSB-K-0 & 81 & 9 & 5 & 5 & 0 & $5 \%$ \\
PSB-K-0.5 & 81 & 9 & 5 & 5 & $0.5 \%$ & $5 \%$ \\
PSB-K-1 & 81 & 9 & 5 & 5 & $1 \%$ & $5 \%$ \\
PSB-K-1.5 & 81 & 9 & 5 & 5 & $1.5 \%$ & $5 \%$ \\
\hline
\end{tabular}




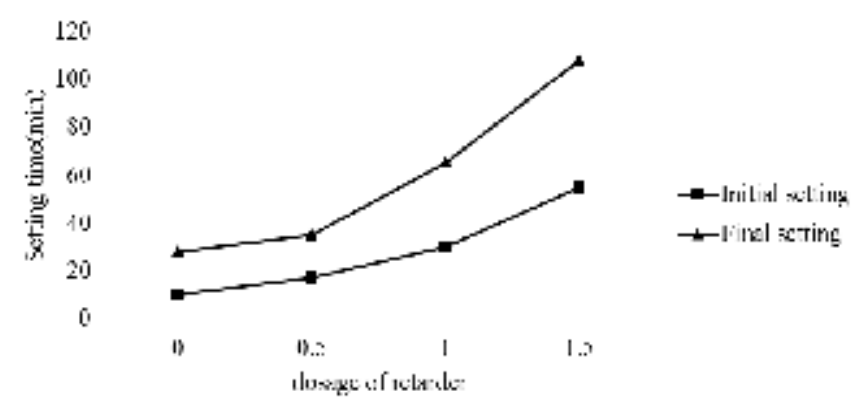

Figure 1. Influence of dosage of retarder $\mathrm{K}$ on setting time of PSBCM.

Effect of SF on property of PSBCM

The silica fume was incorporated to improve the workability of mortar specimens of PSBCM. The mix proportion of PSB-SF specimens and the strength results were shown in Table 4.

Table 4. Effect of content of silica fume on the strength of PSBCM.

\begin{tabular}{|c|c|c|c|c|c|c|c|}
\hline \multirow[t]{2}{*}{ No. } & \multicolumn{5}{|c|}{$\begin{array}{l}\text { Composition of cementitious } \\
\text { material(by weight ratio) } \\
(\%)\end{array}$} & \multirow{2}{*}{$\begin{array}{l}\mathrm{Na} 2 \mathrm{SiO} 3 \\
(\mathrm{Cal} . \mathrm{as} \\
\mathrm{Na} 2 \mathrm{O})\end{array}$} & \multirow[t]{2}{*}{ K } \\
\hline & P.S & P.O & GT & $\mathrm{A}$ & SF & & \\
\hline PSB-SF-0 & 81 & 9 & 5 & 5 & 0 & $5 \%$ & $1 \%$ \\
\hline PSB-SF-1 & 80 & 9 & 5 & 5 & 1 & $5 \%$ & $1 \%$ \\
\hline PSB-SF-2 & 79 & 9 & 5 & 5 & 2 & $5 \%$ & $1 \%$ \\
\hline PSB-SF-3 & 78 & 9 & 5 & 5 & 3 & $5 \%$ & $1 \%$ \\
\hline \multirow{2}{*}{ No. } & \multicolumn{4}{|c|}{$\begin{array}{l}\text { Flexural strength } \\
(\mathrm{MPa})\end{array}$} & \multicolumn{3}{|c|}{$\begin{array}{l}\text { Compressive } \\
\text { strength }(\mathrm{Mpa})\end{array}$} \\
\hline & $1 d$ & $3 d$ & & $28 \mathrm{~d}$ & $1 \mathrm{~d}$ & $3 d$ & $28 \mathrm{~d}$ \\
\hline PSB-SF-0 & 3.6 & 5.6 & & 8.2 & 16.3 & 29.4 & 45.2 \\
\hline PSB-SF-1 & 3.1 & 5.1 & & 8.7 & 13.5 & 30.4 & 47.1 \\
\hline PSB-SF-2 & 3.5 & 5.7 & & 11.5 & 16.1 & 27.2 & 49.6 \\
\hline PSB-SF-3 & 2.9 & 4.5 & & 8.6 & 12.6 & 25.5 & 56.3 \\
\hline
\end{tabular}

The workability of PSBCM mortar specimens was improved obviously after the incorporation of silica fume. The fluidity of this specimens were in $160 \sim 200 \mathrm{~mm}$. Silica fume possessed large specific surface area and its fine particles could adsorb more free water, thus increased the viscosity of PSBCM to improve its workability. From Table 4, it is implied that the early strength of PSBCM were slightly decreased, but the later strength was increased after mixing silica fume. The content of $2 \%$ of silica fume was optimal to enhance the property of PSBCM.

Through the experiments above, the optimal mix proportion of PSBCM with rapid hardening and high early strength was determined as PSB-SF-2 in Table 4. Based on the mix proportion, paste and mortar samples were made to test its properties. The results were displayed in Table 5.

The Table 5 showed that the 1-d mortar flexural strength and mortar compressive strength of PSBCM prepared were $3.5 \mathrm{MPa}$ and $16.1 \mathrm{MPa}$, respectively, achieving the expected aim of strength requirements of GB175-2007 for ordinary Portland cement P.O42.5R.

Table 5. The test results of properties of PSBCM based on the optimal mix proportion.

\begin{tabular}{llllllll}
\hline $\begin{array}{c}\text { Setting time } \\
(\mathrm{min})\end{array}$ & \multicolumn{3}{c}{$\begin{array}{c}\text { Flexural strength } \\
(\mathrm{MPa})\end{array}$} & \multicolumn{4}{c}{$\begin{array}{c}\text { Compressive } \\
\text { strength }(\mathrm{MPa})\end{array}$} \\
\hline Initial & Final & $1 \mathrm{~d}$ & $3 \mathrm{~d}$ & $28 \mathrm{~d}$ & $1 \mathrm{~d}$ & $3 \mathrm{~d}$ & $28 \mathrm{~d}$ \\
\hline 30 & 65 & 3.5 & 5.7 & 11.5 & 16.1 & 27.2 & 49.6 \\
\hline
\end{tabular}


Microstructure of the hardened paste of PSBCM

The microstructure of hardened paste of PSB-SF-2 at the age of $12 \mathrm{~h}, 3 \mathrm{~d}$ and $28 \mathrm{~d}$ were shown in SEM images (Figure 2).

The SEM images confirmed that the microstructure of hardened paste of PSBCM was compacted, which with gelatinous flocculent amorphous hydration products in the age of 12 hours could hardly observe in the age of $3-\mathrm{d}$, and in the age of $28-\mathrm{d}$, a more intensified structure was formed than that of $3 \mathrm{~d}$ without much more contline.

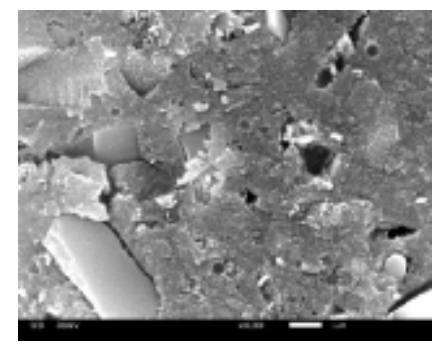

$12 \mathrm{~h}$

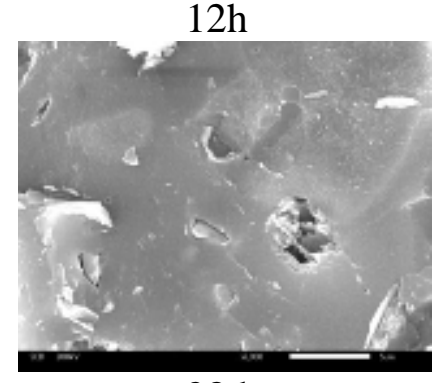

$28 \mathrm{~d}$

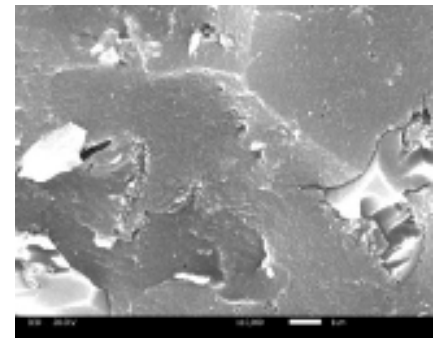

$3 d$

Figure 2. SEM images of hardened paste of PSB-SF-2.

Preparation of phosphorous slag-based cementitous material concrete

Three strength grades (C30-PS, C40-PS, andC50-PS) of phosphorous slag-based concrete were prepared according to PSB-SF-2, and a cement-based concrete (C50) was prepared as a reference group. The mix proportion of concrete and its physical and mechanical properties were given in Table 6 and Table 7.

The Table 7 notes that the physical and mechanical properties of phosphorous slag-based concrete were good to meet the required performance of high early strength and fast hardening, and the workability of phosphorous slag-based concrete was better than that of Portland cement concrete with the same strength grade.

Table 6. Concrete mix proportion of different strength grade.

\begin{tabular}{|c|c|c|c|c|c|}
\hline \multirow{2}{*}{ No. } & \multicolumn{5}{|c|}{ mix proportion $\left(\mathrm{kg} / \mathrm{m}^{3}\right)$} \\
\hline & PS & P.O & GT & $\mathrm{HL}$ & $\mathrm{SF}$ \\
\hline C30-PS & 237 & 27 & 15 & 15 & 6 \\
\hline C40-PS & 304 & 35 & 19 & 19 & 7.7 \\
\hline C50-PS & 365 & 42 & 23 & 23 & 9 \\
\hline C50 & / & 463 & l & I & l \\
\hline \multirow{2}{*}{ No. } & \multicolumn{4}{|c|}{ mix proportion $\left(\mathrm{kg} / \mathrm{m}^{3}\right)$} & \multirow{2}{*}{$\begin{array}{l}\text { Water binder } \\
\text { ratio }\end{array}$} \\
\hline & $\mathrm{K}$ & $\mathrm{Na} 2 \mathrm{O}$ & Sand & Stone & \\
\hline C30-PS & 3 & 15 & 651 & 1264 & 0.6 \\
\hline C40-PS & 3.8 & 19 & 622 & 1208 & 0.48 \\
\hline C50-PS & 4.6 & 23 & 596 & 1157 & 0.40 \\
\hline $\mathrm{C} 50$ & / & / & 596 & 1157 & 0.40 \\
\hline
\end{tabular}

Note: C50 used cement P.O42.5 
Table 7. Physical and mechanical properties of concrete with different strength grades.

\begin{tabular}{lllllll}
\hline \multirow{2}{*}{ No. } & $\begin{array}{l}\text { Slump } \\
(\mathrm{mm})\end{array}$ & \multicolumn{2}{l}{$\begin{array}{l}\text { Setting } \\
\text { time(min) }\end{array}$} & \multicolumn{4}{c}{$\begin{array}{l}\text { Compressive } \\
\text { strength/MPa }\end{array}$} \\
\cline { 3 - 7 } & & Initial & Final & $3 \mathrm{~d}$ & $7 \mathrm{~d}$ & $28 \mathrm{~d}$ \\
\hline C30-PS & 220 & 52 & 79 & 21.1 & 23.9 & 39.7 \\
C40-PS & 180 & 43 & 66 & 25.9 & 31.7 & 43.9 \\
C50-PS & 150 & 25 & 41 & 30.3 & 38.3 & 59.5 \\
C50 & 55 & 150 & 210 & 24.4 & 32.3 & 48.6 \\
\hline
\end{tabular}

\section{CONCLUSION}

(1)The physical and mechanical properties of PSBCM were improved through the incorporation of mineral material $\mathrm{A}$, retarder $\mathrm{K}$ and silica fume. The optimal mix proportion of PSBCM was that the content of phosphorous slag was $79 \%$, while the contents of graphite tailings, Portland cement, mineral material A and silica fume were $5 \%, 9 \%, 5 \%$ and $2 \%$, respectively. As the incorporation of sodium silicate $(5 \%$, Cal.as $\mathrm{Na} 2 \mathrm{O})$ as well as chemical A $(1 \%)$ in PSBCM, the mortar compressive strength of the material in the age of $1 \mathrm{~d} 、 3 \mathrm{~d} 、 28 \mathrm{~d}$ were $16.1 \mathrm{MPa} 、 27.2 \mathrm{MPa}$ and $49.6 \mathrm{MPa}$, respectively, and that of mortar flexural strength were $3.5 \mathrm{MPa} 、 5.1 \mathrm{MPa}$ and $11.5 \mathrm{MPa}$, respectively, which reached the strength requirement of Chinese Standard GB 175-2007 for ordinary Portland cement P.O42.5R. Scanning Electronic Microscope demonstrated that the early hydration of PSBCM was fast and its microstructure was compacted that made the optimal mix proportion possessed the properties of rapid hardening and high early strength.

(2) Three strength grades of phosphorous slag-based cement concretes were prepared based on the optimal mix proportion of PSBCM .The test results showed that the physical and mechanical properties of these concretes were good and at the same strength level, the properties of phosphorous slag-based concrete was better than that of Portland cement -based concrete.

\section{ACKNOWLEDGEMENTS}

This research work was financially supported by the Open Fund of State Key Laboratory of Silicate Materials for Architecture in Wuhan University of Technology (grant No. SYSJJ2014-05), the Science and Technology Supporting Project of Hubei province (grant No. 2014BCB035) and the Graduate Innovation Fund of China Three Gorges University(grant No.2015CX020).

\section{REFERENCE}

[1]Zhu Chenggui, 2006.Alkali - phosphorus slag cementing materials research. Nanjing: nanjing university of technology. (in Chinese)

[2]Chen Ming, Sun Zhengping, Liu Jianshan,2013. State of the art review on activating techniques and mechanism of phosphorus slag. Mater. (in Chinese).

[3] Gao Xuwei, Wu Yonsheng, The current comprehensive utilization and developing tendency of phosphorus slag[J]. China resources comprehensive utilization, 2010, 28(1): 28-30. (in Chinese)

[4]Shi caijun, Zheng keren, 2008. Alkali activated cement and concrete. Beijing: chemical industry press. (in Chinese)

[5] Zhang Wenxue, Nie Guiping, Li Qiang, et al, 2003. Study on rapid repair materials of cement concrete pavement, Foreign building materials science and technology,24 (1): 11-14. (in Chinese)

[6] Gao xiaojian, Yang yingzi, Deng hongwei, Li Manxi,2010. Research on rapid repairing material for concrete structures undergone natural disaster. Journal of sichuan university (engineering science edition). 42 (2):40-45. (in Chinese)

[7] Peng yanzhou, Zhang jun, Xu gang, Liu jiuyan, Guo shengqi, Li zhenwei,2015. Preparation and microstructure of phosphorous slag-based cementitious material with high early strength. $J$ of china three gorges univ.(natural sciences).12(6):15-19. (in Chinese) 
[8] He Juan, Yang changhui, Kang sufang,2010. Research progress on problem of petarding of alkali-activated slag cement. Bulletin of the chinese ceramic society.29(5):1093-1097. (in Chinese)

[9] Young Nanru ,2000.Inorganic material atlas manual Wuhan: wuhan university press. (in Chinese). 